\title{
Motor Capabilities of Lower Limb Amputated Patients and Its Relation to Body Image and Depression
}

\author{
Sabah S. Hassan*1 Hend E. Mohammed ${ }^{2}$ \\ 1.Psychiatric and Mental Health Nursing, Faculty of Nursing, Minia University, Egypt \\ 2.Medical-Surgical Nursing, Faculty of Nursing, Minia University, Egypt
}

\begin{abstract}
Background: Lower limb amputation is a great event in the life of individual's which having an counteractive effect on overall physical, psychological and social functioning of an individual so the study aim is to measure relation of motor capabilities of lower limb amputated patients on body image and depression level. Methods: Design: The descriptive correctional research design was utilized to achieve the aim of the study. Sample: A convenient sample of sixty four participant consisted of male and female adult amputee patients. Setting: This study was conducted in Rheumatology and Rehabilitation Department at Minia University Hospital. Tools of data collection: Three scales and one tool were utilized; Bio socio-demographic characteristic and structured interview, Locomotor Capabilities Index, Amputee Body Image Scale and Beck Depression Inventory (BDI) scale. Results: $73.5 \%$ of the amputated patients have low locomotor capabilities while $93.7 \%$ of the study sample has a low body image and $31.2 \%$ of the study sample suffers from moderate depression after 6 month from amputation and high positive significant correlation between locomotor capabilities and body image, while that there was a high negative significant correlation between locomotor capabilities and depression level among the imputed patients. Conclusions: The recent amputee patients that are have lower limb prosthesis suffer from low locomotor capabilities and theses have negative impact on their body image and depression level. Recommendation: A well planned structured rehabilitation program should be done to the specific needs of people with limb amputation in order to be able to find out its impact on their functional abilities, body image and depression level.
\end{abstract}

Keywords: Amputation, locomotors capabilities, Body image, Depression.

DOI: $10.7176 / \mathrm{JHMN} / 64-03$

Publication date:July $31^{\text {st }} 2019$

\section{Introduction}

Moxey et al. (2011) defined Lower Extremity Amputations (LEA) as the removal of lower limbs for many factors by surgery e.g. tumor, trauma, congenital abnormalities, orthopedic complications, diabetics or due to Peripheral Arterial Occlusive Disease (PAOD). LEA is classified to minor and major LEA; a minor LEA is defined as an amputation through, or distal, to the ankle joint. The removal of toes, forefoot (trans-metatarsal) or any excision of tissue below the ankle are commonly performed and allow a functional level of mobility post operatively (Svensson et al. ,2011). While (Uzzaman et al., 2011) defined a major LEA as removal of the limb from the ankle joint or above, i.e. trans-tibia amputation (TTA), through knee amputation (TKA), trans-femoral amputation (TFA), hip disarticulation (HD) and hemi-pelvectomy (HP) levels.

A lower extremity amputation is a lasting disabling surgery; were performed because of Peripheral Arterial Occlusive Disease (PAOD) whereas it consider a lifesaving and pain relieving, and is the health of an individual were improved. However, this comes at the cost to the individual in terms of affecting their ability to function on a daily basis. Lower extremity amputations also have wider implications, as they are associated with increased levels of anxiety and depression, altered body image and social discomfort, all of which are a psychological burden for the patient and their family (Horgan \& MacLachlan, 2004). In the same context (Lewis, 2009) who reported that, cure from amputation is a very hard journey. Whereas thought of losing an anatomical part is a destructive to the most of people when it happens, amputation causes a threefold loss in terms of function, sensation and body image.

The concept of body image encompasses the way in which a person feels that his or her body image will affect interactions, playing a significant role in social and interpersonal relationships. This mental image incorporates perceptions of and attitudes towards appearance, functionality, and sexuality. The concept also includes a person's opinion of how their body image influences intimate and social interactions, allowing it to significantly affect various relationships. Therefore the changes in appearance that many people endure as a result of trauma or disease can completely alter one's pre-existing body image and take him or her far from his ideal body image. (Bessel et al., 2012). In the same respect (McRobert, 2012) mentioned that, alterations in body image are due to an individual being incapable to adapt to the appearance change. These changes in body image set up "a series of emotional, perceptual, and psychological reactions.

The studies performed by (Holzer, et al., 2014) on body image in amputees, it was discovered that amputees generally disclose negative feelings regarding their bodies. When an individual has a limb amputated, the person 
tends "to compare the appearance of his or her body and functional capabilities to others'," which makes it difficult "for the amputee to have a positive attitude toward his or her body" Due to this, it is thought to potentially lead to a long-term disorder in an individual's body experience .However, prosthetic devices have been used for hundreds of years to assist amputees in preserving their quality of life and supporting them in their activities of daily living. Great strides have been and are being made by increasingly skilled and educated prosthetic professionals that positively affect the ever-demanding user population (Cochrane, et al., 2001).

Mozumdar \& Roy (2012) defined depression as a mood disorder that is characterized by the feeling of hopelessness, constant sadness, loss of interest or pleasure, sleep disturbances and decrease functional ability. In addition, depression is having a deep influence on our daily lives as it is connected and associated with many counteractive health conditions and lower socioeconomic status. A person habitual of thinking bad and thinking negatively about one's self are more prone to get depressed.

De Sousa (2013) added that, persons who lost their body parts may have posttraumatic stress disorders in very foremost stages of his her life which later in life turns to severe depression and other psychiatric disorders.

Amputation is a kind of triple threat to an individual. It involves loss of function, loss of sensation, and loss of body image. The disability arising from amputation gives rise to depression in those people. Karira et al (2013). In the same context (Mansoor et al., 2010) founded that, one of the main reasons of depression is societal negative attitude and functional limitation of the person having any disease or disability. It has been seen that the amputees attending surgical or rehabilitation clinics, 20 to $60 \%$ of them are assessed as being clinically depressed. Additionally the body image problems is another main factor which contributes to depression and have been found among people with amputations and these have been associated with increased activity restriction.

Prosthetics is very closely related to amputation, as it is oftentimes what is done to compensate for the lost limb. Prosthetics is defined as the making and fitting of artificial body parts; therefore, prosthesis is an artificial body part. Approximately $68-88 \%$ of amputees wear their prosthesis at least seven hours each day to assist them in mobility and help them perform their activities of daily living. Gailey (2011). In this respect (Murray, 2009) mentioned that, one's everyday activities are restricted when the prosthetic limb is not used because it serving functional needs, the prosthesis also acts as a device to hide the amputation and to reinstitute an intact body image to the individual. "The use of prosthesis could be an important tool and mediator between disability and emotional well-being". Using prosthesis has the potential for significantly increasing one's psychological health and also improving body image with limb loss.

McRobert (2012) concluded that, due to the belief that individuals must face a sequence of confrontations in order to adjust to disfigurement, the significance of social and family support in the process of adjusting to a changed appearance should be stressed, so there is a need for emotional support whereas staff nurses and other healthcare professionals can assist in improve the consequences of this problem. Nurses should concern with psychological issues in their patients. In addition, it is crucial that they provide support "to encourage patients to confront their injuries and gradually expose disfigurements to the public" because this can have "a very positive effect when helping patients to adjust"

\section{Significant of the study}

Amputation leads to a lasting individual disability. Lower limb amputations are more disabling and much more common than upper limb amputations because they affect directly on the walking ability (Mahima et al., 2017). It raise the social burden by influencing the ability to proceed activities and the level of independence of an individual and have adverse effect on the body image and depression level of amputee patient. So, based on the preceding study's findings this study was performed to analyze the relationship of motor capabilities for recent lower limb prosthesis among amputated patient on body image and depression level.

\section{Aim of the study}

The aim of the present study was to measure relation of motor capabilities of lower limb amputated patients on body image and depression level.

\section{Research hypothesis}

Motor disabilities of recent lower limb prosthesis among amputate patients have negative effect on their body image and depression.

\section{Subjects and Methods \\ Research Design:}

The descriptive correlational research design was utilized in the current study. Setting:

This study was carried out in Rheumatology and Rehabilitation Department at Minia University Hospital. 


\section{Study Duration:}

The total data collection was starting from October 2016 to December 2017.

Subjects:

A convenient sample of (64) patients was assigned in the current study.

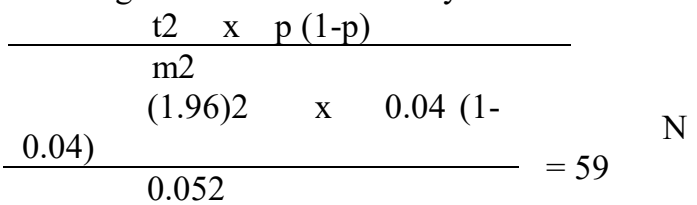

The subjects of the current study were selected according to the following inclusion criteria:

\section{Inclusion criteria:}

1. Adult male and female $(20-60$ years $)$.

2. Conscious and oriented.

3. Complete primary wound healing (a period of at least six months after amputation).

\section{Exclusion criteria:-}

1. Patient with bilateral lower limb amputation.

2. Those that had open wounds

3. Diseases that would impede gait patterns i.e. traumatic brain injury, spinal cord injury or other neurological problems.

4. Patient who not wear prosthesis.

\section{Tools of data collection}

Three scales and one tool were utilized to collect pertinent data for this current study.

Tool 1: Biosocio-demographic characteristic and structured interview questionnaire. It was developed by the researchers after revising extensive literature review. It was collected at the first interview and it covers two main parts:

Part one: The socio-demographic data for the patient such as age, sex, residence, marital status..... etc).

Part two: The medical-surgical information data such as (types and indication of amputation..... etc).

Scale 1: Locomotor Capabilities Index (LCI)

This scale was used to assess ability to perform activities and the level of independence while performing these activities. Developed by (Grise et al., 1993). It consists of 14 items that measure one general construct; two subscales emerge from this general construct; basic abilities ( 7 items) and advanced abilities ( 7 items). Each of the 14 items is graded on a 4-point ordinal scale; 0 (not able to), 1 (yes, with help from other person), 2 (yes, if someone is near me), 3 (yes, alone, with ambulation aids) and 4 (yes, alone, without ambulation aids).

Scoring system the total LCI score is the sum of the item scores and can range from 0 (worst) to 54 (best). The score of (0-18) is given when the patient low locomotor capabilities, while a score of (19-36) is given for the moderate locomotor capabilities subsequently a score of (37-56) high locomotor capabilities. The LCI is intended for self-administration but can also be administered in a face-to-face or telephone interview.

\section{Scale 2: Amputee Body Image Scale.}

This scale created by (James, 1997). It is composed form twenty-item of Likert scale that is designed to measure how an amputee perceives and feels about his or her body experience. The patients were asked to indicate their responses to the questions using the following scale: (1) none of the time, (2) rarely, (3) some of the time, (4) most of the time, and (5) all of the time. This scale produces scores that range from 20-100, with high scores indicating high body image disturbance. Three questions (question 3, 12 and 16) are reverse-scored.

Scoring system the total score of Amputee Body Image scale is the sum of the item scores and can classified into, the score of (1-40) is given when the patient had low body image, while a score of (41-80) is given for the normal body image subsequently a score of (81-120) highly body image.

\section{Scale 3: Beck Depression Inventory (BDI) scale}

It is used to measures characteristic attitudes and symptoms of depression developed by (Beck, et al., 1961). Is a series of questions developed to measure the intensity and severity of depression? It composed of 21 questions; each designed to assess a specific symptom common among people with depression.

The long form of the BDI is composed of 21 questions or items, each with four possible responses. Each response is assigned a score ranging from zero to three, indicating the severity of the symptom. Individual questions of the BDI assess mood, pessimism, and sense of failure, self-dissatisfaction, guilt, punishment, selfdislike, self-accusation, suicidal ideas, crying, irritability, social withdrawal, body image, work difficulties, insomnia, fatigue, appetite, weight loss, bodily preoccupation, and loss of libido. Items 1 to 13 assess symptoms that are psychological in nature, while items 14 to 21 assess more physical symptoms.

The sum of all BDI item scores indicates the severity of depression. For the general population, a score of 21 or over represents depression. For people who have been clinically diagnosed, scores from 0 to 9 represent 
minimal depressive symptoms, scores of 10 to 16 indicate mild depression, scores of 17 to 29 indicate moderate depression, and scores of 30 to 63 indicate severe depression. The BDI can distinguish between different subtypes of depressive disorders, such as major depression and dysthymia (a less severe form of depression).

\section{Validity of tools}

The tools was tested for the content validity by a jury of (3) experts in the field of the study (Minia University) to identify the degree to which the used tools measure what was supposed to be measured, content coverage , clarity, wording length, format and overall appearance . Based on their recommendation, all jury members agree that the current study tools were valid and relevant with the aim of the study.

\section{Reliability of tools}

The Amputee Body Image Scale reliability is 0.88 . The current study computed a Cronbach's alpha of the resulted in 0.92. While internal consistency for the BDI ranges from 0.73 to 0.92 with a mean of 0.86 (Beck, Steer, \& Garbin, 1988). The BDI demonstrates high internal consistency, with alpha coefficients of 0.86 and 0.81 for psychiatric and non-psychiatric populations respectively (Beck et al., 1988). LCI internal consistency was determined using Cronbach alpha coefficient and the 95\% confidence intervals (CI) were calculated using the bootstrap method. Values between 0.70 and 0.95 have been proposed to indicate good internal consistency.

\section{Pilot study}

A pilot study was carried out on 6 patients $(10 \%)$ of the total sample to test feasibility, objectivity and applicability of the tools.

\section{Ethical Consideration}

An official permission to conduct the current study was obtained from the Dean of nursing faculty and Minia university hospital director. Written consents were obtained from subjects who were informed about the purpose, procedure, benefits, nature of the study, follow-up and they had the right to withdraw from the study at any time without any rationale. Confidentiality and anonymity of each subject were ensured through coding of all data and protecting the obtained data.

\section{Procedure}

The current study was conducted by preparing of different data collection tools, in addition obtaining formal paper agreement which was taken induration one month before conducting the study. Collection of study data was done through daily basis ( 2 days per week) during morning shift.

Selected sample was admitted to Rheumatology and Rehabilitation Department at Minia University Hospital was informed by the researchers individually about purpose and nature of the study, then researchers obtained oral consent from those who accepted to participate in this study. The researchers have started a collection of data using the first tool (Bio socio-demographic characteristics) and after that the researchers collect the three study scales through face to face interview to evaluate the extent of recent amputee patients that are wear prosthesis, what are level of independence while performing some motor activities by using first scale (Locomotors Capabilities Index), this scale that are collected in 5 to $10 \mathrm{~min}$ for every patient and after that assess the amputee patient perceives and feels about his or her body experience and measures characteristic attitudes and symptoms of depression through the second and third scales

\section{Statistical analysis of data}

Data were summarized, tabulated, and presented using descriptive statistics in the form of frequency distribution, percentages, means and the standard deviations as a measure of dispersion. A statistical package for the social science (SPSS), version (20) was used for statistical analysis of the data, as it contains the test of significance given in standard statistical books. Numerical data were expressed as mean and SD. F-test or (ANOVA) has been utilized for multiple groups. Pearson correlation analysis was used for assessing the inter-relationships between quantitative variables. Statistical significance was considered at $p$ value $\leq 0.05$. 


\section{Result}

Table (1): Distribution of the Socio demographic Characteristics of the Study Sample. (n= 64).

\begin{tabular}{|c|c|c|}
\hline \multirow[t]{2}{*}{ Items } & \multicolumn{2}{|r|}{$\begin{array}{c}\text { Study group } \\
N=64\end{array}$} \\
\hline & $\mathbf{N}$ & $\%$ \\
\hline \multicolumn{3}{|l|}{ Age: } \\
\hline $41: 50$ years & 26 & 40.7 \\
\hline 51:64 years & 38 & 59.3 \\
\hline Mean \pm SD & \multicolumn{2}{|c|}{$58.0 \pm 18.81$} \\
\hline \multicolumn{3}{|l|}{ Sex } \\
\hline Male & 36 & 56.3 \\
\hline Female & 28 & 43.8 \\
\hline \multicolumn{3}{|l|}{ Occupation: } \\
\hline House wife & 12 & 18.7 \\
\hline Farmer & 8 & 12.5 \\
\hline Worker & 10 & 15.6 \\
\hline Employment & 18 & 28.2 \\
\hline Retired & 16 & 25 \\
\hline
\end{tabular}

Table (1): Shows that, about more than half of the study sample were males and $59.3 \%$ their age ranged from 51:64 years. $28.2 \%$ were having governmental work.

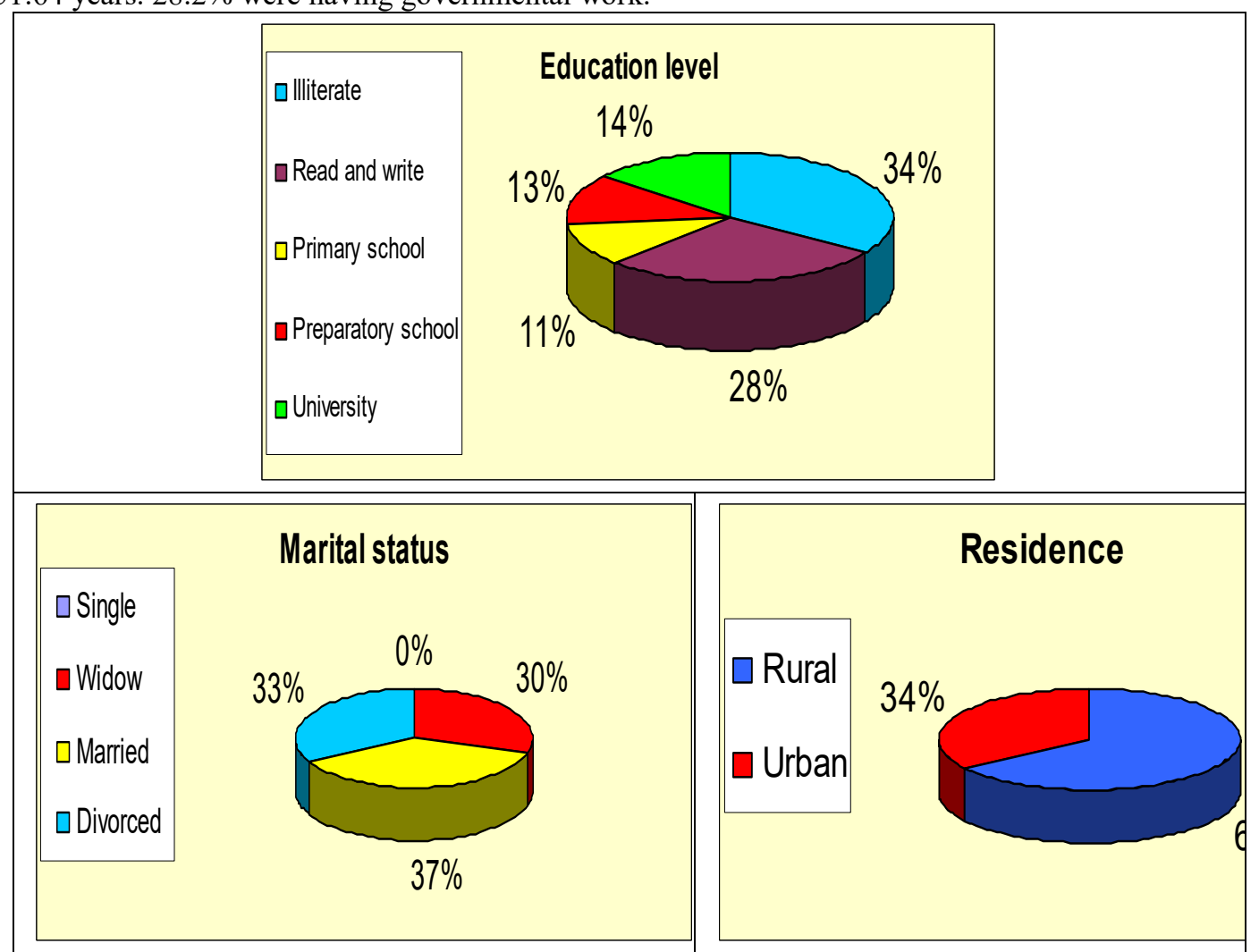

Figure (1): Distribution of patients according to their educational level, marital status and residence

Figure (1): Shows that, the educational level revealed that $28 \%$ had a read and write only. $66 \%$ of the study sample was living in rural areas and $37 \%$ of them were married. 


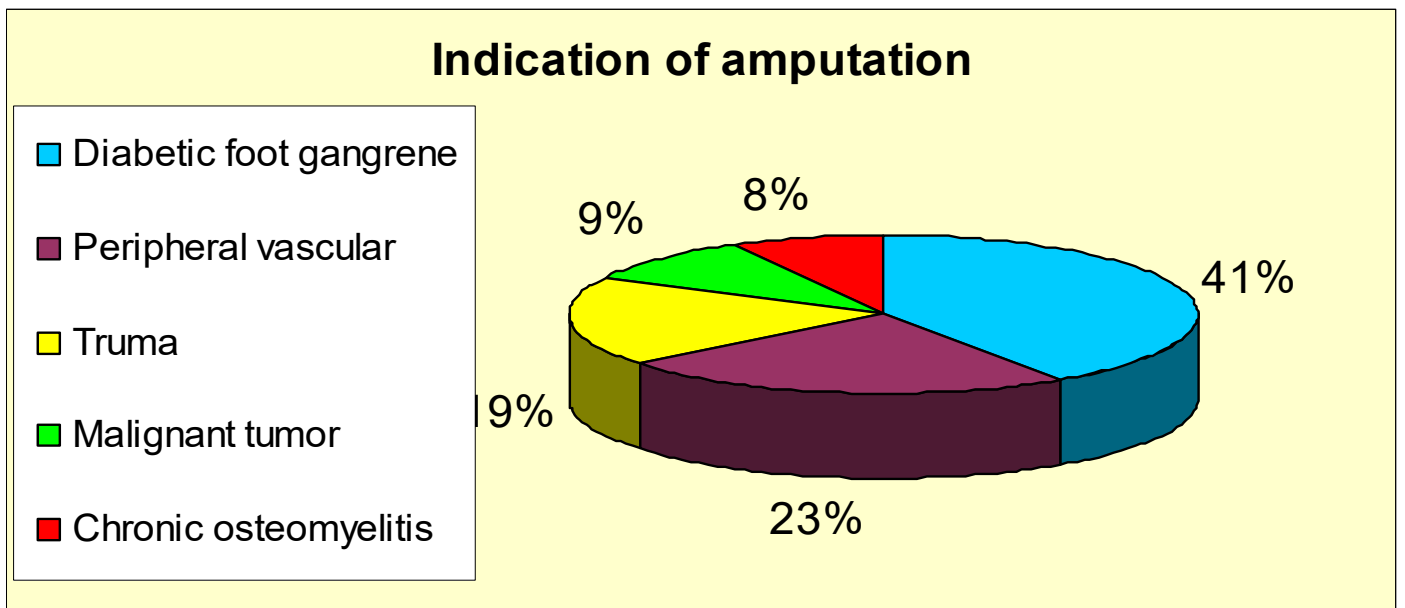

Figure (2): Distribution of the study sample related to their causes and indication that participating amputation $(n=64)$

Figure (2): reveals that, the first precipitating factor for the amputation is diabetic foot and gangrene $41 \%$, while the peripheral vascular causes consider the second causes of amputation and represented as $23 \%$ from study sample.

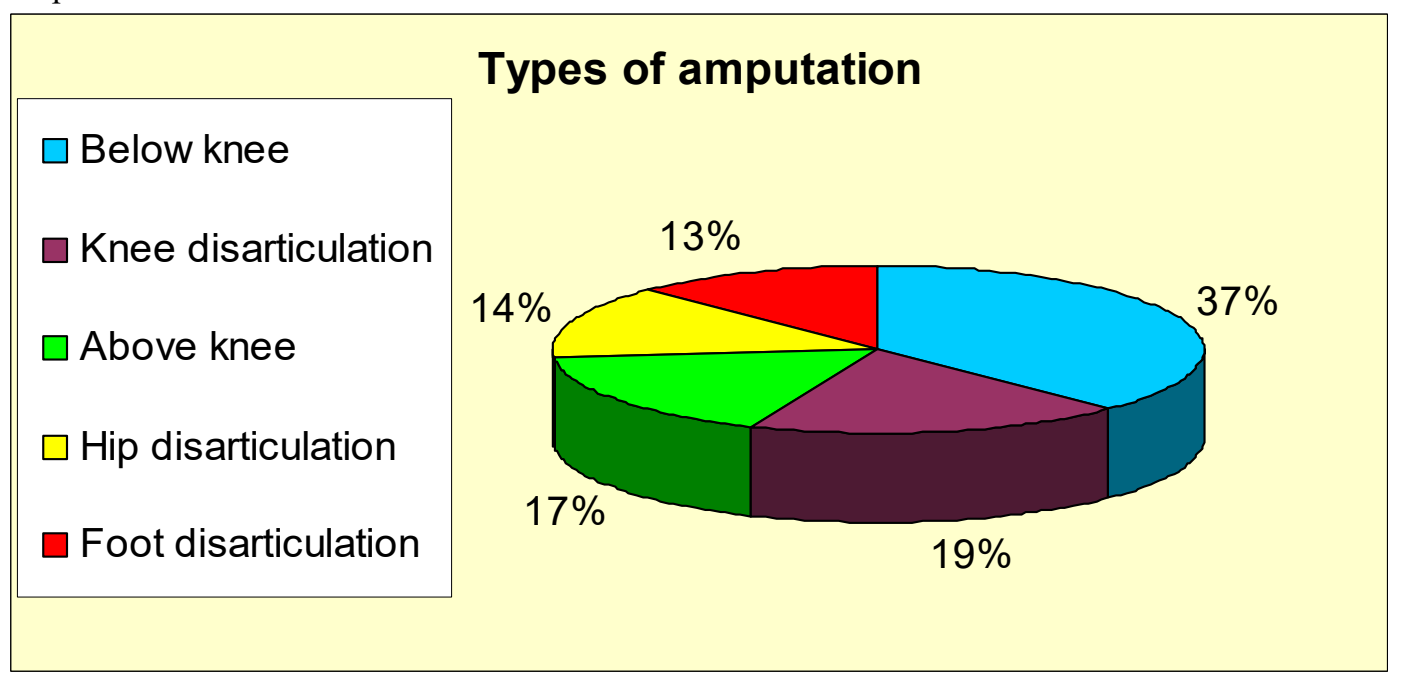

Figure (3): Distribution of study sample according to the frequency about level of amputation.

Figure (3): Shows that, the level of amputation of study sample revealed that $37 \%$ had amputee the leg below the knee and 19\% of the study sample imputed the leg at knee disarticulation.

Table (2): Distribution of the study sample according to locomotor capabilities index in amputees (LCI)

\begin{tabular}{|l|c|c|}
\hline \hline \multirow{2}{*}{ Items } & \multicolumn{2}{c|}{ Study (n=64) } \\
\cline { 2 - 3 } & No. & \% \\
\hline 1- Low locomotor capabilities & 47 & 73.5 \\
\hline 2- Moderate locomotor capabilities & 17 & 26.5 \\
\hline 3- High locomotor capabilities & 0 & 0 \\
\hline \hline
\end{tabular}

Table (2): it is clear from the above table that the majority of the study sample $(73.5 \%)$ had low locomotor capabilities after amputation 6 month.

Table (3). Distribution of the study sample according to body image scale among amputated patients

\begin{tabular}{|l|c|c|}
\hline \hline \multirow{2}{*}{ Items } & \multicolumn{2}{|c|}{ Study (n=64) } \\
\cline { 2 - 3 } & No. & \% \\
\hline 1- Low body image & 60 & 93.7 \\
\hline 2- Normal body image & 4 & 6.2 \\
\hline 3- Highly body image & 0 & 00 \\
\hline \hline
\end{tabular}

Table (3): shows that the $93.7 \%$ of the study sample has a low body image after amputation 6 month. 
Table (4): Distribution of the study sample according to level of depression among amputated patients

\begin{tabular}{|l|c|c|}
\hline \hline \multicolumn{1}{|c|}{ Items } & \multicolumn{2}{c|}{ Study (n=64) } \\
\cline { 2 - 3 } & No. & \% \\
\hline 1- Normal depression & 4 & 6.2 \\
\hline 2- Mild mood disturbance & 6 & 9.4 \\
\hline 3- Border line clinical depression & 13 & 20.4 \\
\hline 4- Moderate depression & 20 & 31.2 \\
\hline 5- Severe depression & 14 & 21.9 \\
\hline 6- Extreme depression & 7 & 10.9 \\
\hline \hline
\end{tabular}

Table (4): shows that, $31.2 \%$ of the study sample suffers from moderate depression after amputation 6 month and $21.9 \%$ had severe depression.

Table (5): Difference between personal data of the study sample and total locomotors capabilities, body image and Depression $n=64$

\begin{tabular}{|c|c|c|c|c|c|}
\hline \multirow[t]{2}{*}{ Variable } & $\begin{array}{c}\text { Total of } \\
\text { locomotors } \\
\text { capabilities }\end{array}$ & $\begin{array}{l}\text { Total of Body } \\
\text { image }\end{array}$ & $\begin{array}{c}\text { Total of } \\
\text { Depression }\end{array}$ & \multirow[t]{2}{*}{ F- test } & \multirow[b]{2}{*}{$\mathbf{P}$} \\
\hline & Mean \pm SD & Mean \pm SD & Mean \pm SD & & \\
\hline \multicolumn{4}{|l|}{ Age: } & \multirow[t]{3}{*}{8.67} & \multirow[t]{3}{*}{$0.001 *$} \\
\hline 41:50 years & $28.4 \pm 5.6$ & $45.6 \pm 5.6$ & $12.6 \pm 8.1$ & & \\
\hline 51:64 years & $32.6 \pm 11.1$ & $75.8 \pm 7.2$ & $28.6 \pm 8.1$ & & \\
\hline \multicolumn{4}{|l|}{ Sex: } & \multirow[t]{3}{*}{1.32} & \multirow[t]{3}{*}{$0.02 *$} \\
\hline Male & $23.5 \pm 1.96$ & $30.2 \pm 5.1$ & $11.6 \pm 4.2$ & & \\
\hline Female & $37.2 \pm 4.26$ & $90.8 \pm 4.5$ & $29.8 \pm 7.2$ & & \\
\hline \multicolumn{4}{|l|}{ Residence: } & \multirow{3}{*}{7.22} & \multirow{3}{*}{$0.001 *$} \\
\hline Rural & $28.8 \pm 4.5$ & $62.4 \pm 6.1$ & $23.3 \pm 4.2$ & & \\
\hline Urban & $32.4 \pm 3.8$ & $58.5 \pm 5.2$ & $17.1 \pm 2.3$ & & \\
\hline \multicolumn{4}{|l|}{ Marital status: } & \multirow{5}{*}{6.16} & \multirow{5}{*}{$0.03 *$} \\
\hline Single & 0 & 0 & 0 & & \\
\hline Widow & $23.8 \pm 3.5$ & $22.2 \pm 4.6$ & $18.2 \pm 4.6$ & & \\
\hline Married & $26.4 \pm 4.2$ & $24.2 \pm 3.6$ & $19.4 \pm 6.2$ & & \\
\hline Divorced & $28.2 \pm 2.1$ & $28.2 \pm 6.2$ & $22.2 \pm 4.3$ & & \\
\hline \multicolumn{4}{|l|}{ Education level } & \multirow{6}{*}{5.23} & \multirow{6}{*}{$0.001 *$} \\
\hline Illiterate & $27.2 \pm 4.2$ & $25.1 \pm 4.3$ & $20.2 \pm 5.2$ & & \\
\hline Read and write & $24.3 \pm 5.2$ & $26.3 \pm 5.2$ & $18.2 \pm 4.2$ & & \\
\hline Primary school & $26.3 \pm 3.2$ & $25.2 \pm 3.2$ & $26.2 \pm 2.3$ & & \\
\hline Preparatory school & $25.2 \pm 4.5$ & $28.2 \pm 2.6$ & $17.2 \pm 5.6$ & & \\
\hline University & $28.2 \pm 2.1$ & $25.1 \pm 3.4$ & $23.2 \pm 2.1$ & & \\
\hline
\end{tabular}

Table (5): Shows that there was a significant statistical difference between loco-motor capabilities, body image and depression scale with demographic characteristic of the study sample.

Table (6): Correlation between loco-motor capabilities, body image and depression scale.

\begin{tabular}{|c|c|c|}
\hline \multirow{2}{*}{ Variable } & $\mathrm{R}$ & \multicolumn{2}{|c|}{ Loco-motor } \\
\cline { 2 - 3 } & $0.921^{* *}$ & $\mathrm{P}$ \\
\hline Body image & $0.911^{*} *_{-}$ & 0.0001 \\
\hline Depression & 0.001 \\
\hline
\end{tabular}

Table (6): Shows that there was a high positive significant correlation between locomotor capabilities scale and body image, while that there was a high negative significant correlation between locomotor capabilities scale and depression level among the imputed patients.

\section{Discussion}

The current study findings showed that more than half of the studied samples were males and $59.3 \%$ their age ranged from 51:64 years with mean age $(58.0 \pm 18.81) .28 .2 \%$ were having governmental work. Furthermore, their educational level revealed that $34 \%$ were illiterate, and the majority of them $66 \%$ living in rural areas and $37 \%$ of them were married. There is agreement between personal data characteristics of the current study with a study conducted by (El Sebaee \& Mohamed, 2011) which show that more than half of the total sample's age ranged from $40-60$ years, with mean age $(50.48 \pm 15.42$ years $)$. As regards gender, and marital status $62 \%$ of the total sample was males and $74 \%$ were married. Considering the educational level, the highest percentage was 
illiterate $42 \%$, and only $26 \%$ had secondary or university level. As regards occupation $54 \%$ were working in manual work, more than two fifth of them were either unemployed or housewife. This may be attributed to similarity of culture.

In addition, this is consistent with the age group representing the study population, supporting the (WHO, 2007) report that the highest incidence of amputation was in the age group of $41-60$ years. Regarding frequency of amputation among gender the current study showed that the high frequency was males, this result contradicted with (Chin-Hsiao, 2006) who mentioned that the prevalence increased significantly with age among men and women equally.

As regards to causes of amputation the findings revealed that the first precipitating factor for the amputation is diabetic foot and gangrene $41 \%$, while the peripheral vascular causes consider the second causes of amputation and represented $23 \%$ from study sample; Increasing amputation rates among individuals with diabetes have been attributed to the fact that the persons with diabetes have poor level of knowledge about diabetes and diabetic foot care. This finding is consistent with the findings of (Htwe et al., 2015) which reported that, diabetes mellitus (DM) was the widespread cause of amputation (63\%) in their study group followed by vascular problems and trauma. While there is incongruent with other studies in which the cause of amputation was trauma in $315(65.49 \%)$ individuals, infection in $121(25.16 \%)$ followed by vascular injury and tumor in decreasing frequency. This may be due to cultural differences factors (Sinha et al., 2011).

According to the type of amputation the present study results revealed that $37 \%$ had a below knee leg amputation. This is consistent with the study conducted by (Agrawal et al., 2017) in which they founded that total individuals with below knee amputation were $340(70.69 \%)$ followed by above knee amputation $127(26.40 \%)$ and trans knee amputation $14(2.91 \%)$. This is explained by the fact that it is a general opinion all over the world amongst surgeons to save as much limb as possible to allow maximum mobility for greater independence.

Regarding to locomotor disability among the studied sample, the results of this study revealed that the majority of the sample $73.5 \%$ of them has low locomotor capabilities after amputation 6 month which predict poor functional outcome after a lower limb amputation. These results were supported by the study results of (Gallagher \& colleagues, 2011) which curried out on a sample of 148 individuals with lower limb amputations. It was found that restrictions in functioning were most commonly experienced especially in the areas of self-care, household chores, sports and physical recreation, leisure and cultural activities, and employment. These findings indicate that the loss of a limb has a negative impact on people's level of participation, thus demonstrating the importance of including this aspect of functioning in examinations of disability among persons with amputations.

In relation to body image disturbance due to amputation our findings revealed that $93.7 \%$ of the study sample has a low body image after amputation. This may be due to the fact that a person's body image is threatened by change in appearance or by a functional change of a body part; the inconsistency between body ideal and body reality can create a negative body image. These findings were supported by the findings of (Desmond et al., 2012) which reported that persons who undergo amputation have severe disturbance in their body image; such disruptions in body image can have an enduring impact on an individual's sense of identity and the nature of their social interactions.

In this respect (Holzer et al., 2014) founded that, lower-limb amputees had a significant lower score in The Multidimensional Body-Self Relations Questionnaire (MBSRQ) as 3.09 \pm 0.55 compared with $3.41 \pm 0.34$ in controls group indicating that a lower-limb amputation is significantly decreases body image perception $(\mathrm{p}<0.001)$. In the same context (Kulkarni, 2014) postulated that, body image changes are considered as a crucial issue in adjustments of limb loss and prosthesis acceptance. It appears to have an immortal relationship with overall psychological adjustments to an amputation. The author added that post amputation body image shows significant outcomes that predict depression, lower rating of adjustment, lower overall Quality of Life and less satisfaction.

In this current study $31.2 \%$ and $21.9 \%$ of the study sample have moderate to severe depression respectively following amputation. These findings are consistent with the findings of (Wegener et al., 2009) they postulated that, rates of major depressive disorder are reported to be as high as $34 \%$ to $35 \%$ for inpatient amputees reporting and $21 \%$ to $35 \%$ for outpatient amputees. While these results are not in conformation with the study findings of (Ghous et al., 2015) in which their study included sample of 110 amputees, 28(25.5\%) were having no depression, 35(31.8\%) were mildly depressed, 16(14.5\%) were borderline depressed, 14(12.7\%) were moderately depressed, $8(7.3 \%)$ were severely depressed and $9(8.2 \%)$ were extremely depressed according to Beck Depression Inventory BDI. The author further explain this level of depression due to use of assistive devices, more trend of visiting rehabilitation centers equipped with latest facilities and greater number of amputees following proper rehab regime all of which not available to our study sample so the depression is high.

Our study findings revealed statistical significant differences between personal data characteristics of the studied sample in relation to total locomotors capabilities, total body image, and total depression with the highest mean score for gender difference is for female this may be explained by that the aesthetic aspects of prosthesis 
satisfaction have a greater influence on body image and depression among females. This is consistent with the study of (Murray, 2010) which reported that, concerns about different aspects of prosthesis use between males and females show that body image and identity are a higher priority for females. While male amputees tend to focus on the functionality of their prostheses, many female amputees are concerned with feminine attractiveness. In addition it confirmed with the study by (Williams \& associates, 2004) which proves that being a female is a significant predictor of greater symptoms of depression at six months after amputation. Moreover, the result of the present study revealed that there is a statistically significant difference between marital status with total locomotors capabilities, total body image, and total depression with the highest mean score is for divorced and this explain the role of family as a source of support and assistance for the patients. These findings are supported by the findings of (Mohammed \& Shebl, 2014) which founded that there is a statistically significant difference between marital statuses with many psychological aspects. The author attributes this to social support from family.

In the present study there was a high significant correlation between locomotor capabilities scale and body image as well as depression level this may be attributed to that, the negative effect of prosthesis on body image increases the sense of depression at the same time the patient is compelled to wear prosthesis most of the time to able to perform daily activity. This is consistent with the study of (Rybarczyk \&Behel, 2008) they reported that poor body image post-amputation puts the amputee at risk for negative outcomes such as increased depression and decreased life satisfaction, quality of life, and activity levels. It is important to most amputees to have an optimal prosthesis, as it is the central part of their post-amputation body image adjustment. The prosthesis is often viewed as an extension of the body, and dissatisfaction with either the functional or aesthetic aspect of the prosthesis could lead to adjustment difficulties.

Moreover these findings were further supported by the findings of (Marshall \& Stansby, 2010) in which they founded that, social discomfort and body image anxiety found among some people with amputations, and these have been associated with a poorer adjustment in terms of greater activity restriction, depression and anxiety. Psychological problems and depression are common following amputation, as part of the emotional adaptation to limb loss.

\section{Conclusion}

The recent amputation patients that are have lower limb prosthesis suffer from low locomotor capabilities when perform basic and advanced activities and behave increase in level of independence especially in the first 6 month from amputated and theses have negative impact on their body image and depression level

\section{Recommendation}

- A well planned structured rehabilitation program should be established which is appropriate to the specific needs of people with limb amputation in order to be able to find out its impact on their functional abilities, body image and depression level.

- Physiotherapists were often not involved early enough in the patient pathway. Structured involvement of physiotherapists in the multidisciplinary team should include pre-operative discussion of rehabilitation potential and the level of amputation as well as early post-operative rehabilitation and co-ordination of discharge plans.

- An educational training protocol planned in a continuous manner and given on regular basis for amputated patients that are have lower limb prosthesis to improve level of dependence toward locomotor activities.

- A replication of the study on a larger sample from different geographical areas should be done to achieve generalization of the results.

\section{References}

1- Agrawal, M,. Kalra, A. and Joshi M. (2017). Correlation of ambulation potential with quality of life in lower limb amputees. International Journal of Community Medicine and Public Health Nov;4(11):42594265.

2- Beck, A.T., Ward, C. H., Mendelson, M., Mock, J., \& Erbaugh, J. (1961) An inventory for measuring depression. Archives of General Psychiatry, 4, 561-571.

3- Beck, A. T., Steer, R.A., \& Garbin, M.G. (1988) Psychometric properties of the Beck Depression Inventory: Twenty-five years of evaluation. Clinical Psychology Review, 8(1), 77-100.

4- $\quad$ Beck AT., Ward CH., Mendelson M., Mock J., Erbaugh J. (1961) an inventory for measuring depression. pubmed jun;4:561-71.J.W. Breakey, Body image: The lower limb amputee, J Prosthet Orthot 9 (1997), 58-66.

5- Bessell, A., Dures, E., Semple, C., \& Jackson, S. (2012). Addressing appearance-related distress across clinical conditions. British Journal of Nursing, 21(19), 1138-1143.

6- Chin-Hsiao, T. (2006). Prevalence of lower-extremity amputation among patients with diabetes mellitus: Is 
height a factor? Canadian Medical Association Journal, January 31, 2006 vol. 174 no. 3: 319-323. doi: 10.1503/cmaj.050680.

7- Cochrane, H., Orsi, K., \& Reilly P. (2001). Lower limb amputation part 3: prosthetics - a 10 year literature review. Prosthetics and Orthotics International (25), 21-28.

8- De Sousa A. (2013) .Post traumatic stress disorder in children. Private Psychiatry. Available from: http:// medical dictionary.thefreedictionary.com/amputation.

9- Desmond, D. M., Coffey, L., Gallagher, P., MacLachlan, M., Wegener, S. T., \& O'Keeffe, F. (2012). Limb amputation. In P. Kennedy (Ed.), The Oxford handbook of rehabilitation psychology. New York: Oxford University Press.

10- El Sebaee H.A, and Mohamed L.A. (2011). Stressors and Positive Coping Strategies among Patients with New Limb Amputation. Journal of American Science ;7(9):726-736].(ISSN: 1545-1003).

11- Gailey, Robert. (2011). Secondary conditions and prosthetic users. Retrieved fromhttp://www.amputeecoalition.org/inmotion/may_jun_11/secondary_conditions.pdf.

12- Gallagher, P., O`Donovan, M. A., Doyle, A., \& Desmond, D. (2011). Environmental barriers, activity limitations and participation restrictions experienced by people 240 with major limb amputation. Prosthetics and Orthotics International, 35(3), 278-284.

13- Gauthier-Gagnon C, Grise' MC. Prosthetic profile of the amputee questionnaire: Validity and Reliability. Arch Phys Med Rehabil. 1994;75:1309- 14.

14- Ghous M, Gul S, Siddiqui FA, Pervaiz S, Bano S. Depression; prevalence among amputees. Professional Med J 2015;22(2):263-266.

15- Grise' MC, Gauthier-Gagnon C, Martineau GG. (1993).Prosthetic profile of people with lower extremity amputation: conception and design of a follow-up questionnaire. Arch Phys Med Rehabil. 74:862-70

16- Horgan, O. and MacLachlan, M. (2004) 'Psychosocial adjustment to lower-limb amputation: A review', Disability \& Rehabilitation, 26(14-15), 837-850.

17- Holzer L.A, Sevelda F., Fraberger G., Bluder O., Kickinger W., and Holzer G. (2014). Body Image and Self-Esteem in Lower-Limb Amputees. PLoS One Journal ; 9(3): e92943. doi: 10.1371/journal.pone.0092943.

18- Hojat, M., Shapurian, R., Mehrya, A.H., (1986). Psychometric properties of a Persian version of the short form of the Beck Depression Inventory for Iranian college students, Psychological Reports, 59(1), 331-338.

19- Htwe O., Suganthini S , Lee K, Maryam S, Fadhil H , Kumaragu S, Joseph L, Tan A, Khin N , Naicker A. ( 2015) . Quality of Life among Lower Limb Amputees Treated at the Tertiary Hospital, Malaysia. International Medical Journal Vol. 22, No. 3, pp. $171-174$.

20- Karira A, Shah N, Joshi D, Goregaonkar A. (2013). Psychiatric disorders in traumatic amputation. Private Psychiatry.24:48.

21- Kulkarni T., Hande D., Parab K. (2014). Body image and quality of life among individuals with lower limb amputation.Indian Journal of Basic and Applied Medical Research: Vol.-3, Issue- 3, P. 63-66.

22- Lewis, Text book of medical and surgical nursing, 7th edition Published by Mosby , (2009) . Page No : 320 325.

23- Mahima A., Kalra, A. S. , Mrinal, J. (2017). International Journal of Community Medicine and Public Health Correlation of ambulation potential with quality of life In lower limb amputees Agrawal M et al. Int J Community Med Public Health.; 4(11):4259-4265 http://www.ijcmph.com pISSN 2394-6032 | eISSN 2394-6040.

24- Mansoor I, Margoob MA, Masoodi N, Mushtaq H, Younis T, Hussain A,. (2010). Prevalence of Psychiatric Co morbidities in Traumatic Amputees-A cross sectional study from Kashmir (Indian Part). British Journal of Medical Practitioners. 2010;3(4).

25- Marshal. C \& Stansby. G. 2010. Journal of Vascular Surgery Amputation and Rehabilitation. 28:284-287. http://www.sciencedirect.com.ezproxy.turkuamk.fi/science? Retrieved on 10.02.2011.

26- McRobert, J. (2012). The psychosocial impact on patients with altered body image from burns. British Journal of Community Nursing, S27-30.

27- Mohammed S. A. and Shebl A. M.. (2014). Quality of Life among Egyptian Patients with Upper and Lower Limb Amputation: Sex Differences. Advances in Medicine. Volume 2014, Article ID 674323, 8 pages http://dx.doi.org/10.1155/2014/674323.

28- Moxey, P. W., Gogalniceanu, P., Hinchliffe, R. J., Loftus, I. M., Jones, K. J., Thompson,M. M. and Holt, P. J. (2011) 'Lower extremity amputations--a review of global variability in incidence', Diabet Med, 28(10), $1144-53$

29- Mozumdar A, Roy SK. (2010). Depression in adult males with lower extremity amputation and its biosocial correlates. Health; 2(8):878-89.

30- Murray, C. D. (2009). Being like everybody else: the personal meanings of being a prosthesis user. Disability \& Rehabilitation, 31(7), 573-581. 
31- Murray, C. D. (2010). Gender, sexuality and prosthesis use: Implications for rehabilitation. In C. D. Murray (Ed.), Amputation, prosthesis use, and phantom limb pain: An interdisciplinary perspective (pp. 115-127). London: Springer.

32- Rybarczyk, B. and Behel, J. (2008). "Limb Loss and Body Image," in Psychoprosthetics, Gallagher, P. Desmond, D. and Maclachlan, M. Eds. London, England: Springer, pp. 23-31.

33- Sinha R, Van den Heuvel WJA, Arokiasamy P. Factors affecting quality of life in lower limbamputees. Prosth Orthot Int. 2011; 35(1):90-6.

34- Steer, R. A., Rissmiller, D. J.\& Beck, A.T., (2000) Use of the Beck Depression Inventory with depressed geriatric patients. Behaviour Research and Therapy, 38(3), 311-318.

35- Svensson, H., Apelqvist, J., Larsson, J., Lindholm, E. and Eneroth, M. (2011) 'Minor amputation in patients with diabetes mellitus and severe foot ulcers achieves good outcomes', journal of wound care, 20(6), 261.

36- Uzzaman, M. M., Jukaku, S., Kambal, A. and Hussain, S. T. (2011) 'Assessing the longterm outcomes of minor lower limb amputations: a 5-year study', Angiology,0003319710395558.

37- Wegener. S. T, Mackenzie. E. J, Ephraim. P, Ehde. D, Williams. R. (2009).Self-Management Improves $\begin{array}{lllll}\text { Outcomes in } & \text { Persons } & \text { with } & \text { Loss. } & \text { 273- }\end{array}$ 380.http://web.ebscohost.com.ezproxy.turkuamk.fi/ehost/pdfRetrieved on 10.02.2011.

38- World Health Organization (2007). Incidence of amputation. Available at: www. emro. WHO. Int 